\title{
Estratégia de capacitação de enfermeiros recém-admitidos em unidades de internação geral
}

\author{
STRATEGY FOR THE QUALIFICATION OF NEWLY HIRED NURSES IN INTERNMENT \\ UNITS FOR GENERAL PURPOSES
}

\author{
ESTRATEGIADE CAPACITACIÓN DE ENFERMEROS RECIÉN ADMITIDOS EN \\ UNIDADES DE INTERNAMIENTO GENERAL
}

Ivana Lucia Correa Pimentel de Siqueira', Paulina Kurcgant ${ }^{2}$

\section{RESUMO}

O objetivo deste artigo é apresentar um programa de capacitação de enfermeiros recémadmitidos, implementado em unidades de internação de um hospital privado de São Paulo. O programa foi estruturado de forma a diminuir o tempo de treinamento e possibilitar a participação dos enfermeiros das unidades de internação. O programa está divido em três fases. A primeira destina-se à revisão técnica. $\mathrm{Na}$ segunda, com um monitor de treinamento, os ingressantes assumem a coordenação assistencial da unidade. Na terceira são revisados rotinas e temas administrativos. Este programa vem apresentando bons resultados em relação à individualização do treinamento e participação dos enfermeiros da instituição.

\section{DESCRITORES}

Capacitação em serviço. Educação continuada em enfermagem.

Hospitais privados.

\begin{abstract}
The aim of this article is to describe a qualification program for newly hired nurses that has been implemented in internment units in a private hospital in São Paulo. The program was designed in such a way as to reduce training time and make possible the participation of the units' nursing staff. It is divided in three phases. Phase 1 is a technical revision. In Phase 2, with the assistance of a training monitor, the trainees take over the assistance coordination of the unit. In Phase 3, administrative routines and topics are revised. This program has been showing good results regarding the individualization of the training and the participation of nurses.
\end{abstract}

\section{KEY WORDS}

In-service training.

Education, nursing, continuing.

Hospitals, private.

\section{RESUMEN}

El objetivo de este artículo es presentar un programa de capacitación de enfermeros recién-admitidos, implementado en unidades de internamiento de un hospital privado de São Paulo. El programa fue estructurado de forma a disminuir el tiempo de entrenamiento y posibilitar la participación de los enfermeros de las unidades de internamiento. El programa está divido en tres fases. La primera se destina a la revisión técnica. En la segunda, con un monitor de entrenamiento, los ingresantes asumen la coordinación asistencial de la unidad. En la tercera se revisan las rutinas y temas administrativos. Este programa viene dando buenos resultados en relación a la individualización del entrenamiento y participación de los enfermeros de la institución.

\section{DESCRIPTORES}

Capacitación en servicio. Educación continuada en enfermería.

Hospitales privados.
1 Gerente de Enfermagem do Hospital Sírio Libanês. Mestre em Enfermagem e Doutoranda da Escola de Enfermagem da Universidade de São Paulo (EEUSP). ivana.siqueira@hsl.org.br

2 Professora Titular do Departamento de Orientação Profissional da EEUSP. 
Ivana Lucia C.P. de Siqueira Paulina Kurcgant

\section{INTRODUÇÃO}

No que se refere a pessoal, a Enfermagem detêm uma grande parcela dos recursos humanos de uma organização hospitalar. Assim, situações de demissão e afastamento, freqüentemente ocorrem, desencadeando a admissão de novos profissionais.

Os enfermeiros ingressantes são, em geral, submetidos a um programa de treinamento antes de assumirem suas funções. A duração, o conteúdo, os métodos adotados, a avaliação dos resultados, as estratégias para a integração do recém-admitido, suas experiências de trabalho e as relações com os profissionais do setor são aspectos fundamentais na elaboração e operacionalização dos programas de capacitação.

Ainda, neste processo, vale tecer algumas considerações. Na atual situação financeira da maioria dos hospitais, o quadro de pessoal não prevê um número de profissionais excedentes para cobertura de ausências, impondo agilidade nas substituições, o que interfere no tempo e conteúdo dos programas de capacitação. Há poucos profissionais de educação continuada nas instituições, dificultando o acompanhamento individualizado do recém-admitido e sua avaliação. Os avanços tecnológicos e científicos aumentam a quantidade e a complexidade das informações a serem trabalhadas, determinando longo tempo destinado aos programas. A falta de planejamento integrado entre o serviço de educação continuada e as áreas utilizadas na realização do treinamento interfere na dinâmica das ações e nos resultados.

Evidencia-se tais apontamentos em um estudo com recém-admitidos, comentando que o planejamento dos programas, a política institucional e os enfermeiros envolvidos no processo podem dificultar ou facilitar o desenvolvimento dos programas de treinamento para ingressantes ${ }^{(1)}$. Em outra pesquisa, identificou-se dificuldades no relacionamento e na realização do trabalho, em unidades em que eram realizados programas de orientação inicial, apontando pouca flexibilidade na operacionalização e falta de envolvimento da equipe $^{(2)}$.

Programas que prestigiam a participação e a valorização do potencial humano parecem ser a solução desta problemática. As pessoas devem ser vistas como parceiros das organizações, pois são fornecedoras de conhecimentos, habilidades, capacidades e impõem significado aos objetivos e rumos organizacionais ${ }^{(3)}$. Outro pesquisador ${ }^{(4)}$ complementa esta idéia, reiterando a importância das oportunidades de participação aos profissionais e o estímulo para o desenvolvimento pessoal e da auto-estima.

Neste sentido, também devem fazer parte deste processo educativo, não somente os enfermeiros da educação continuada, mas também os profissionais atuantes no campo de trabalho. A aproximação do ingressante do local de trabalho e a observação da realidade oportunizam conteúdos programáticos atualizados e compatíveis às necessidades assistenciais e administrativas. Há autor ${ }^{(3)}$ que apóia a utilização do próprio local de trabalho para o desenvolvimento das atividades educativas, referindo constar de uma possibilidade de vivenciar o contexto onde ocorrem os fatos.

Quanto aos conteúdos, ressalta-se que há uma tendência dos serviços de enfermagem em buscarem programas que não contemplem a situação da realidade vivenciada ${ }^{(5)}$. Outro pesquisador ${ }^{(1)}$ complementa, referindo que os programas são demasiadamente voltados para normas e rotinas institucionais, além de aspectos tecnológicos, não valorizando a atuação prática. É apontado, em um estudo, que os enfermeiros, técnicos e auxiliares de enfermagem preocupam-se com a parte prática dos programas de treinamento, entendendo-a como a mais relevante ${ }^{(6)}$. Estes autores reiteram a necessidade de revisão periódica dos conteúdos e o alinhamento destes com a prática profissional, a fim de facilitar o processo de capacitação. Também, reforçam a idéia da participação da equipe, tanto na construção dos conteúdos quanto na operacionalização dos programas.

A participação dos enfermeiros nos programas contribui para a adequação dos conteúdos, para a avaliação das necessidades do ingressante, além de propiciar a troca de experiências e reafirmar o seu papel na educação da equipe ${ }^{(1)}$. O compartilhamento de informações fortalece as relações e evidencia as competências dos profissionais. Assim como existe autor ${ }^{(7)}$ que transcende esta idéia, comentando que

\footnotetext{
na antiga visão organizacional o poder significava a manutenção das informações só para si e, atualmente, em uma empresa bem sucedida, o verdadeiro poder está em compartilhar as informações com os diferentes níveis organizacionais.
}

Ainda, no que tange à melhoria desse processo, algumas iniciativas vêm sendo documentadas. O treinamento individualizado é apontado 
como uma proposta que propicia flexibilidade de horários, avaliação detalhada, ganho de tempo, aperfeiçoamento de instrutores e diminuição de erros pela diminuição do fluxo de informações ${ }^{(8)}$. A utilização de meios, não somente verbais, para a transmissão de informações como filmes, dinâmica de grupo, videoconferência e programas computadorizados contribuem para a dinamização do processo e fixação de idéias ${ }^{(9)}$.

Frente ao desafio de propor soluções que contemplem os requisitos da capacitação do profissional recém-admitido, em tempo hábil, contando com o envolvimento da equipe e satisfação dos envolvidos, faz-se necessário lançar mão de novas estratégias.

Vivenciando esta preocupação em uma instituição que se encontra em processo de expansão, com admissão de profissionais para a equipe de enfermagem e poucos enfermeiros do serviço de educação continuada, reestruturamos o programa de capacitação. O presente artigo refere-se a um relato de experiência sobre a elaboração e aplicação desse programa de capacitação de enfermeiros recém-admitidos na área de internação geral em um hospital privado de São Paulo.

O objetivo é apresentar o programa de capacitação, sua base teórica, estruturação, operacionalização e avaliação.

\section{O PROGRAMA DE CAPACITAÇÃO PARA ENFERMEIROS INGRESSANTES}

Este programa teve início nas áreas de internação geral devido à inauguração de novas unidades. A primeira aplicação do programa deu-se em 1998, quando o hospital dispunha de 150 leitos neste setor, sendo que cada unidade possuía de 21 a 24 apartamentos. Havia 50 enfermeiros nesta área. A unidade de educação continuada dispunha de quatro enfermeiros, sendo um, especificamente para o atendimento dessas unidades, juntamente com o enfermeiro encarregado desse serviço, que também participava, ativamente, das propostas.

O programa foi concebido pela enfermeira assistente $d a$ gerência de enfermagem, uma das autoras deste trabalho, com a colaboração dos enfermeiros encarregados das unidades de internação e enfermeiros da educação continuada. A assistente da gerência de enfermagem era responsável pela coordenação das unidades de internação e implantou um modelo de gestão, no qual se insere esta proposta. Este modelo de gestão, inclusive, é objeto de estudo de uma tese desenvolvida pelas autoras.

\section{A base teórica do programa}

Este programa foi concebido à luz dos conceitos do Desenvolvimento de Competências.

Os estudos sobre competências tiveram início na década de 70 por David C. McClelland, com a criação de técnicas que possibilitavam o destaque de variáveis de comportamento referentes à avaliação de habilidades, aptidões e atitudes ${ }^{(10)}$.

A competência é a capacidade de transformar conhecimento e habilidades em entrega ${ }^{(11)}$. Outro autor ${ }^{(12)}$ define competência como

\begin{abstract}
a transformação de conhecimentos, aptidões, habilidades, interesse e vontade em resultados práticos. Ter conhecimento e experiência e não saber aplicá-los em favor de um objetivo, de uma necessidade, de um compromisso, significa não ser competente.
\end{abstract}

De acordo com esta metodologia, o trabalho de uma determinada área é explorado intensamente a fim de serem captadas as competências necessárias para sua realização. São estudados: a missão da área e os principais objetivos; o elenco de atividades desenvolvidas de acordo com as diferentes fases de atuação do profissional, ou seja, na adaptação após a admissão, na execução do trabalho após o treinamento e em relação ao desenvolvimento da liderança da equipe para obtenção de resultados; os resultados esperados, segundo a política institucional e os indicadores de eficácia estabelecidos; o conhecimento tecnológico a ser utilizado; o relacionamento e contatos necessários para o desenvolvimento do trabalho; as aptidões e habilidades gerais e específicas para o desenvolvimento da função; as condições de trabalho de acordo com o ambiente e fatores ergonômicos; e, as características do profissional atuante.

Estes itens tornaram possível a recomposição do trabalho e do papel do enfermeiro, direcionando, o educador e o treinando, para as habilidades a serem desenvolvidas. As aptidões dos recémadmitidos são captadas pelos instrutores, durante o período de treinamento, podendo-se destinar tempos diferentes aos conteúdos do programa dependendo dos desempenhos individuais, além de reforços em determinadas competências ou também, o engajamento do profissional em atividades que vão além das planejadas, como participação em reuniões, eventos, ministração de aulas, entre outras atividades coerentes com suas aptidões. Permite ainda, auxiliar na recolocação de profissionais nas diferentes áreas de trabalho de acordo com seu perfil.
Estratégia de capacitação de enfermeiros recém-admitidos em unidades de internação geral

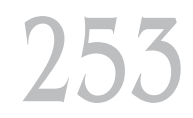

Rev Esc Enferm USP 2005; 39(3):251-7. 
Ivana Lucia C.P. de Siqueira Paulina Kurcgant
Quanto à avaliação do ingressante está baseada em princípios que pressupõem um processo dinâmico, construído diariamente, sob um enfoque de promoção, de melhorias e não de anúncio de falhas. Sabe-se que neste período, ocorre uma tendência à insegurança e à incerteza, de ambas as partes, que podem ser amenizadas por este processo. A competência é o atributo mais importante das pessoas e a referência para promoção e remuneração ${ }^{(12)}$.

\section{A estrutura do programa}

O programa foi estruturado com a finalidade de capacitar os enfermeiros para o exercício da nova função e vem sendo realizado, no hospital em estudo, até os dias de hoje.

Os objetivos específicos do programa eram: envolver a equipe das unidades de internação no processo de desenvolvimento; diminuir o tempo destinado ao treinamento para 42 dias (eram 75 dias); e vincular o processo avaliativo aos enfermeiros das respectivas unidades de internação (a avaliação era realizada, apenas, pelos enfermeiros da educação continuada).

As estratégias adotadas foram: nomear e preparar monitores de treinamento, os quais seriam responsáveis pelo desenvolvimento das atividades do ingressante na unidade de trabalho; construir a idéia de "amadrinhamento" dos treinandos pelos monitores; utilizar as unidades hospitalares especializadas de acordo com o conteúdo programático; dividir as atividades entre enfermeiros da educação-continuada, enfermeiros das unidades e chefias; delegar a decisão de aprovação do recém-admitido ao monitor; e, utilizar um roteiro de atividades que auxiliasse no direcionamento das ações (Anexo).

O programa consta de três fases para sua realização, ou seja, a primeira com os enfermeiros da educação continuada, a segunda com o monitor de treinamento e a terceira com o enfermeiro encarregado da unidade de internação. Estas fases estão explicadas a seguir.

\section{Primeira fase - Unidade de Educação Continuada}

Os enfermeiros da unidade de educação continuada promovem discussões, demonstração e avaliação de todos os procedimentos de enfermagem, utilizando diversas estratégias como filmes, dinâmica grupal, manequins educativos e situações simuladas. Esta fase acontece na unidade de educação continuada, em sala de aula e em labora- tórios de simulação, estando presentes todos os ingressantes da área de enfermagem do período.

Após, ainda com os enfermeiros da unidade de educação continuada, praticam a assistência integral aos pacientes em uma das unidades da instituição, buscando a realização do máximo de procedimentos possível. As competências técnicas ficam evidenciadas nesta fase, bem como são observadas outras habilidades do profissional, sendo todas as informações registradas, desencadeando-se o processo avaliativo.

Esta fase dura cerca de duas semanas.

\section{Segunda fase - Acompanhamento pelos monitores de treinamento}

Nesta fase acontece a saída do enfermeiro, do grupo de recém admitidos, e seu ingresso na unidade onde ocupará seu posto efetivo. A partir de então é acompanhado pelos monitores de treinamento.

Os monitores são enfermeiros, da própria unidade, que após indicação, participam de um programa de capacitação. De um modo geral, acontece um elenco de reuniões com participação dos futuros monitores e profissionais especialistas das diversas áreas da instituição e convidados externos, que buscam o desenvolvimento e aprofundamento de temas relacionados à assistência, administração e ensino. Algumas sessões para execução de procedimentos de enfermagem e manipulação de equipamentos fazem parte do programa.

No acompanhamento dos recém-admitidos, os monitores seguem o roteiro de atividades. Este auxilia o monitor a organizar gradativamente a integração do treinando ao trabalho da unidade. Uma apostila com textos sobre patologias, tratamentos e assistência de enfermagem é fornecida ao recém-admitido. Desencadeia-se um processo no qual, diariamente, durante cerca uma semana, monitor e enfermeiro ingressante discutem sobre determinado sistema do organismo e assumem o planejamento de cuidados e assistência dos pacientes com as patologias referentes aos temas estudados. Busca-se com isto, a integração teoria-prática. O monitor pode programar-se para utilizar outras unidades de internação como campo de trabalho de acordo com as especialidades e interesse. Após assistirem os pacientes com as patologias sugeridas pelo roteiro, na semana seguinte, passam, gradativamente, a aumentar o número de pacientes sob seus cuidados, até contemplarem a coordenação assistencial de metade da unidade. 
Os enfermeiros, incluindo o encarregado da unidade, estabelecem um trabalho de parceria com o monitor, colaborando no desenvolvimento das atividades. As unidades trabalham com dois enfermeiros por turno, sendo o monitor um deles, o qual está envolvido no treinamento do recém-admitido. Assim, o enfermeiro encarregado passa a auxiliar no desenvolvimento do trabalho assistencial da unidade. A partir da segunda semana, o enfermeiro recém-admitido e o monitor, à medida que ampliam o número de pacientes sob seus cuidados, colaboram, gradativamente, com o colega de plantão na divisão do trabalho, liberando o enfermeiro encarregado dessa atividade. O monitor e o recémadmitido mantêm os mesmos dias de folgas durante esse período.

Em geral, são necessárias três semanas para esta fase, dependendo da experiência profissional e desempenho do ingressante.

\section{Terceira fase - Acompanhamento pelo monitor $e$ enfermeiro encarregado e avaliação final}

Trata-se de um período, em que paralelamente ao desenvolvimento habitual do trabalho na unidade, são programadas discussões da dupla, monitor e ingressante, com o enfermeiro encarregado da unidade. Discutem sobre temas administrativos ligados à prática de enfermagem como: filosofia de serviço, liderança, modelos de prestação de assistência, custos, trabalho em equipe, ética e comunicação interpessoal. Ainda, são apresentadas ou ratificadas as rotinas burocráticas e administrativas institucionais que fazem parte do cotidiano de trabalho, valendo apontar que grande parte delas já foram experienciadas pelo recémadmitido.

Esta experiência constitui uma oportunidade de estabelecimento de uma relação com a chefia da unidade.

A avaliação é concretizada nesta fase, mediante as considerações dos enfermeiros da unidade, enfermeiro-encarregado e monitor, sendo este último, o responsável pela decisão final.

Este período pode variar de uma semana a duas, dependendo das necessidades e do desempenho de cada profissional.

\section{CONSIDERAÇÕES FINAIS}

A avaliação dessa nova proposta permite considerar que os objetivos específicos do programa de capacitação foram atendidos.
O tempo destinado ao programa vêm sendo adequado, possibilitando o desenvolvimento e a avaliação do recém-admitido. Vale apontar que até o fim do programa, cerca de 42 dias, o monitor consegue avaliar, claramente, as condições do colega, o que vêm dando maior segurança na tomada de decisão de aprovação ou reprovação.

Os monitores, compartilhando do programa e atuando junto ao ingressante, acabam por tornaram-se tutores do colega, exibindo atitudes de compromisso e responsabilidade pelos resultados. A estratégia de individualizar o treinamento e deslocar a avaliação para o monitor, permitiu a constituição de uma relação de cumplicidade entre ingressante e monitor.

A capacitação dos monitores apresentou-se como uma estratégia para o aperfeiçoamento profissional, com vistas à repercussão na qualidade do trabalho, propiciando também motivação entre o grupo de enfermeiros.

A possibilidade da ocorrência do treinamento, na maior parte do tempo, na unidade de internação, facilitou a integração do enfermeiro recém-admitido e propiciou a colaboração da equipe, uma vez que sua entrada representa reforço no contingente de pessoal local.

A divisão do trabalho entre a unidade de educação continuada, monitores e enfermeiros encarregados, permitiu dinamizar o processo admissional, liberando os enfermeiros da educação continuada para constituírem mais grupos de iniciantes, bem como realizarem atividades educacionais nas diversas áreas, o que ficava comprometido, anteriormente.

Observou-se que este programa permite a consideração das experiências anteriores do recémadmitido, propiciando a evidência das suas competências e flexibilidade de tempo para o desenvolvimento daquelas que se apresentam necessárias, de acordo com a evolução de cada um. Ainda, permitiu que aqueles ingressantes que possuem experiências ou habilidades compatíveis aos programas científicos e educacionais vigentes na organização pudessem participar na ministração de aulas e na coordenação de discussões.

A avaliação do recém-admitido foi realizada de forma contínua, iniciando-se no setor de educação continuada com a observação e desenvolvimento das competências técnicas; prosseguindo com o monitor que avalia e colabora no desenvolvimento das competências relacionais, técnicas, administrativas e éticas; e, finalmente, ratificada na terceira fase, com a avaliação, que reúne monitor,
Estratégia de capacitação de enfermeiros recém-admitidos em unidades de internação geral 
Ivana Lucia C.P. de Siqueira Paulina Kurcgant enfermeiro encarregado e recém-admitido, estando a decisão vinculada ao monitor.

Devido aos resultados obtidos, o programa foi consolidado nessas unidades, com vistas à expansão para outras.

Considerou-se que a adoção de programas de capacitação que estimulam a participação e permitem a individualização do treinamento devem ser mais estudados. Vale enfocar que o desenvolvimento de competências se insere nas propostas participativas, pela crença de que todos têm competências a serem desenvolvidas. Trata-se assim de uma maneira construtiva de se perceber o outro e de se desenvolver a cooperação e a solidariedade.

\section{REFERÊNCIAS}

(1) Bezerra ALQ. Treinamento do enfermeiro recémadmitido: visão do treinador e do treinando. [dissertação] São Paulo (SP): Escola de Enfermagem da USP; 1995.

(2) Morgan GASG de. Estudo da representação do enfermeiro recém-formado em seu primeiro emprego e suas expectativas em relação ao programa de orientação. [dissertação] São Paulo (SP): Escola de Enfermagem da USP; 1992.

(3) Chiavenato I. Gestão de pessoas: o novo papel dos recursos humanos nas organizações. Rio de Janeiro: Campus; 1999.

(4) Curado I. Mitos e realidades da gestão de recursos humanos. Rev Adm Emp 1995; 2(6):6-8.

(5) Kurcgant P. Educação continuada: caminho para a qualidade. Rev Paul Enferm 1993; 12(2):66-71.
(6) Cunha MA. No palco das ilusões: sobre a educação continuada e suas vicissitudes. [dissertação] São Paulo (SP): Faculdade de Saúde Pública da USP; 1999.

(7) Drucker PF. Admirável mundo do conhecimento. HSM Manag 1997; 1:63-8.

(8) Leeds D. Treinamento individualizado: como aperfeiçoar esta técnica. T\&D 1997; 56:50-1.

(9) Franco D. Uma revolução na educação e no treinamento. T\&D 1996; 46:14-5.

(10) Spencer Jr LM, Spencer SM. Competence at work. New York: John Wiley; 1993.

(11) Dutra JS. Administração de carreiras. São Paulo: Atlas; 1996.

(12) Resende E. O livro das competências. Rio de Janeiro: Qualitymark; 2000.

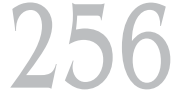

Rev Esc Enferm USP $2005 ; 39(3): 251-7$.

\section{ANEXO}

\section{Roteiro de treinamento para enfermeiros recém-admitidos}

\section{Primeira fase}

Realização de procedimentos, manipulação de equipamentos, discussões e simulações e Assistência de enfermagem integral a pacientes internados:

Sinais vitais; cuidados de higiene, troca de roupa de cama/situações especiais; precauções universais e isolamento; cuidados com medicações e punção venosa; cuidados no preparo e administração de medicações; conectores e injetores para medicação endovenosa, diluições e interação medicamentosa; nutrição parenteral; curativos: tipos, indicações e cuidados; cateterismo vesical (demora e alívio); irrigação, lavagem vesical e manipulação de dispositivos de coleta de diurese; manipulação de ostomias; manipulação e passagem de sondas naso-gástricas; administração de dietas e medicamentos por sondas; desobstrução, drenagem, ordenha, controles de sondas; aspiração naso/orotraqueal; manipulação de drenos; lavagem intestinal, lavagem vaginal; controle de glicose na urina e sangue; auxílio na passagem de cateteres; manipulação de cateteres 
implantados, semi-implantados e periféricos; preparo de óbito; avaliação da dor e condutas; coleta de exames; administração de sangue e derivados; manuseio de equipamentos de uso geral: bomba de infusão/ maca/ maca balança/ Bird/ Emerson/ ECG/ Desfibrilador/ materiais ortopédicos/ marcapasso; atendimento a PCR: estratégia, equipamentos, atuação da equipe; cuidados com o material contaminado e esterilizado; cuidados com pacientes com material radioativo.

\section{Segunda fase}

Discussão sobre a visita de enfermagem; exame físico geral e entrevista; observação das condições do ambiente físico; informações para os acompanhantes.

Sistema Neurológico: discussão sobre o sistema neurológico, exame neurológico, principais patologias, sinais, sintomas, diagnóstico e tratamento. Selecionar um caso neurológico na unidade de internação e proceder à visita de enfermagem. Elaborar histórico, prescrição de enfermagem, segundo levantamento de problemas, anotações pertinentes e as justificativas dos cuidados solicitados, além de todas as documentações rotineiras da unidade. Assistir integralmente o paciente. Realizar a evolução de enfermagem.

Seguem-se nos próximos dias a escolha de pacientes, para prestação de assistência, com distúrbios respiratórios, cardíacos, vasculares, abdominais, ortopédicos, urológicos, nefrológicos e oncológicos. Deverão ser selecionados pacientes clínicos e cirúrgicos. Diariamente deve-se aumentar o número de pacientes assistidos, sendo que a partir do quarto dia, a prestação de cuidados passa a ser assumida pelos auxiliares da unidade.

\section{Terceira fase}

Discussão e entrega de material para leitura. Temas: filosofia de serviço, liderança, modelos de prestação de assistência, custos, trabalho em equipe, ética, comunicação interpessoal, trabalho em equipe, motivação, aspectos legais trabalhistas e políticas de recursos humanos, planejamento e organização do trabalho. Repasse das rotinas de admissão, transferência, alta, óbito, solicitação de medicamentos e descartáveis, solicitação de serviços especializados e médicos.
Estratégia de capacitação de enfermeiros recém-admitidos em unidades de internação geral
Correspondência: Ivana Lucia C. P. Siqueira Hospital Sírio Libanês Rua Dona Adma Jafet, 91 Bela Vista - São Paulo CEP -01308-050 - SP 